$\mathrm{NAD}(+)$ prevents diminished $\mathrm{O}(2)$ consumption by immunostimulated Caco- 2 cells. Am J Physiol Lung Cell Mol Physiol. 2002;282: L1082-91.

7. Szabó C. Pathophysiological aspects of cellular pyridine nucleotide metabolism: focus on the vascular endothelium. Review. Acta Physiol Hung. 2003;90:175-93.

8. Bianchi C, Wakiyama H, Faro R, Khan T, McCully JD, Levitsky S, et al. A novel peroxynitrite decomposer catalyst (FP-15) reduces myocardial infarct size in an in vivo peroxynitrite decomposer and acute ischemia-reperfusion in pigs. Ann Thorac Surg. 2002;74:1201-7.

9. Pacher P, Liaudet L, Bai P, Mabley JG, Kaminski PM, Virág L, et al. Potent metalloporphyrin peroxynitrite decomposition catalyst protects against the development of doxorubicin-induced cardiac dysfunction. Circulation. 2003;107:896-904.

doi:10.1016/j.jtcvs.2004.02.004

\section{Interventional atrial incision in the Fontan operation: Novel prophylaxis or iatrogenic substrate for intra- atrial reentrant tachycardia?}

\section{To the Editor:}

In the March 2004 issue of the Journal, Collins and colleagues ${ }^{1}$ published shortterm results of their interesting prospective, randomized, blinded trial to assess the feasibility, safety, and efficacy of an interventional atrial incision placed at the time of the Fontan operation to reduce the development of intra-atrial reentrant tachycardia (IART). Although the idea sounds clever, there are serious concerns about the longterm efficacy of their modification.

Staged palliation culminating in a successful Fontan procedure is the current surgical goal for most patients with a functional single ventricle. Since its introduction in 1968, the Fontan procedure has undergone many modifications. ${ }^{2}$ At present, two modifications in common use are the lateral tunnel and extracardiac conduit. ${ }^{3}$ The incidence of late supraventricular tachycardia after a lateral tunnel procedure varies from $0 \%$ to $22 \%$, and that after an extracardiac conduit operation varies from $0 \%$ to $8 \% .^{3}$ These figures definitely do not justify undertaking a prophylactic procedure for IART in all patients who undergo Fontan operation in the modern era. It is extremely difficult to predict with accuracy the patients who will definitely have IART.

An even more important concern is the high incidence of early sinus node dysfunction among the study patients. Early sinus node dysfunction may carry long-term im- plications because it predicts late sinus node dysfunction, ${ }^{4}$ which in turn is associated with late supraventricular tachycardia. ${ }^{5}$ Although Collins and colleagues ${ }^{1}$ attributed this high incidence to a "broad definition" of sinus node dysfunction, I think that the interventional atrial incision may be partially if not wholly responsible for this phenomenon. There is a consensus of opinion that the presence of a region of structural or functional block within the atria is a substrate for atrial muscle reentry. ${ }^{5}$ The Fontan operation results in regions of structural block as a result of atrial incisions and multiple suture lines, as well as functional block from relative right atrial hypertension with right atrial dilation and hypertrophy. ${ }^{5}$ The "prophylactic atrial incision" not only will act as region of structural block in the long term but probably interferes with the blood supply of the sinus node in the short term. This could well explain the high incidence of early sinus node dysfunction in the study.

In conclusion, the high prevalence of atrial arrhythmias is a result of extensive atrial surgical procedures, elevated atrial pressures, and atrial enlargement. Until modifications aimed at avoiding atrial manipulation are discovered, earlier identification of sinus node dysfunction with early institution of atrial pacing may be the best prophylaxis to decrease the incidence of IART in this group of patients. My message for Collins and colleagues in particular and readers in general is that any "prophylactic atrial incision" made with the best of intentions will act as nothing but a substrate for IART.

Shahzad G. Raja, MRCS

Department of Paediatric Cardiac Surgery Alder Hey Hospital

Eaton $R d$

Liverpool L12 2AP, United Kingdom

\section{References}

1. Collins KK, Rhee EK, Delucca JM, Alexander ME, Bevilacqua LM, Berul CI, et al. Modification to the Fontan procedure for the prophylaxis of intra-atrial reentrant tachycardia: short-term results of a prospective randomized blinded trial. $J$ Thorac Cardiovasc Surg. 2004;127:721-9.

2. Fontan F, Baudet E. Surgical repair of tricuspid atresia. Thorax. 1971;26:240-8.

3. Kumar SP, Rubinstein CS, Simsic JM, Taylor AB, Saul JP, Bradley SM. Lateral tunnel versus extracardiac conduit Fontan procedure: a concurrent comparison. Ann Thorac Surg. 2003;76:1389-96.

4. Cohen MI, Bridges ND, Gaynor JW, Hoff- man TM, Wernovsky G, Vetter VL, et al. Modifications to the cavopulmonary anastomosis do not eliminate early sinus node dysfunction. J Thorac Cardiovasc Surg. 2000; 120:891-900.

5. Fishberger SB, Wernovsky G, Gentles TL, Gauvreau K, Burnett J, Mayer JE, et al. Factors that influence the development of atrial flutter after the Fontan operation. J Thorac Cardiovasc Surg. 1997;113:80-6. doi:10.1016/j.jtcvs.2004.03.043

\section{Reply to the Editor:}

The Fontan population is heterogeneous in terms of the underlying anatomy and number and nature of surgical interventions before the Fontan operation. Many factors are thought to be associated with the development of atrial arrhythmias in this group. Animal studies have suggested that surgical incision and extended suture lines are particularly likely to create an arrhythmogenic substrate. ${ }^{1-3}$ The more recent versions of the Fontan procedure (lateral tunnel or the extracardiac conduit) have had lower reported incidences of late atrial arrhythmias than the older types of Fontan operations. ${ }^{4}$ Long-term follow-up of the extracardiac conduit Fontan operation has not yet been reported with respect to arrhythmia, but Stamm and colleagues ${ }^{4}$ have recently shown that the lower incidence of atrial tachycardia in the lateral tunnel Fontan procedure persisted through a mean 10year follow-up. ${ }^{4}$ One can interpret this finding to mean that the current Fontan techniques are in fact less arrhythmogenic then was initially projected when our study was undertaken. If so, placement of an interventional atrial incision to the lateral tunnel Fontan may not be warranted in every case, only for patients deemed at higher risk (eg, with a preoperative history of atrial tachycardia).

Although avoiding atrial manipulation and suture lines altogether has theoretic benefits, it is not practical in all cases. If atrial suture lines are required for the surgical intervention, then choosing to place or extend them in such a way to reduce the likelihood of atrial arrhythmias is warranted. Our interventional atrial incision to the lateral tunnel Fontan procedure was designed to transect potential arrhythmia circuits around the atriotomy or the right atrioventricular valve, the primary areas where atrial arrhythmias typically develop. It was designed to be simple, to be feasible in patients with varied anatomy, and to have low added risks for the patient. The location of the incision is inferior to the 
sinus node or the blood supply to the sinus node. The interventional incision will not act as a substrate for atrial arrhythmias because there is no atrial tissue surrounding the incision around which a tachycardia circuit could propagate; the incision is anchored on either end by the nonconducting boundaries of the atriotomy and the right atrioventricular annulus. In fact, treatment of atrial arrhythmias by the Fontan revision surgeries with the right atrial maze procedures are designed create conduction block by similar but more extensive means. ${ }^{5}$

I agree that early postoperative sinus node dysfunction is associated with the development of late sinus node dysfunction and late atrial tachyarrhythmias. In our clinical trial, we reported a high percentage of early sinus node dysfunction in both the control and intervention groups, with no statistically significant difference between the two groups. Thus the sinus node dysfunction seen in this study was not attributable to the interventional atrial incision.

Our study reported only the short-term outcomes of our interventional atrial incision for the prevention of intra-atrial reentrant tachycardia in the lateral tunnel Fontan population. We have learned that, in contrast to previous clinical and animal studies, inducible perioperative atrial arrhythmias were not especially common clinically in these patients. Following up our cohort to assess long-term arrhythmia prevalence will provide a useful addition to our knowledge of the arrhythmia substrate in the Fontan population.

Kathryn K. Collins, MD University of California, San Francisco 521 Parnassus, C-346, Box 0632 San Francisco, CA 94117

\section{References}

1. Gandhi SK, Bromberg BI, Rodefeld MD, Schuessler RB, Boineau JP, Cox JL, et al. Spontaneous atrial flutter in a chronic canine model of the modified Fontan operation. J Am Coll Cardiol. 1997;30:1095-103.

2. Gandhi SK, Bromberg BI, Rodefeld MD, Schuessler RB, Boineau JP, Cox JL, et al. Lateral tunnel suture line variation reduces atrial flutter after the modified Fontan operation. Ann Thorac Surg. 1996;61:1299-309.

3. Rodefeld MD, Bromberg BI, Schuessler RB, Boineau JP, Cox JL, Huddleston CB. Atrial flutter after lateral tunnel construction in the modified Fontan operation: a canine model. J Thorac Cardiovasc Surg. 1996;111: 514-26.

4. Stamm C, Friehs I, Mayer JE, Zurakowski D, Triedman JK, Moran AM, et al. Long-term results of the lateral tunnel Fontan operation. J Thorac Cardiovasc Surg. 2001;121:28-41.

5. Deal BJ, Mavroudis C, Backer CL, Johnsrude CL, Rocchini AP. Impact of arrhythmia circuit cryoablation during Fontan conversion for refractory atrial tachycardia. Am J Cardiol. 1999;83:563-8.

doi:10.1016/j.jtcvs.2004.04.003

\section{Ventral cardiac denervation: Is it truly an effective prophylaxis against atrial fibrillation after coronary artery bypass grafting?}

\section{To the Editor:}

We read with interest the article by Melo and colleagues ${ }^{1}$ on ventral cardiac denervation (VCD) as a prophylaxis against atrial fibrillation (AF) after coronary revascularization. However, we wish to point out certain aspects of the methodology that may have affected the results. Post-CABG $\mathrm{AF}$ is paroxysmal in a large proportion of patients and does not always give rise to clinical symptoms. The fact that only $34 \%$ and $33 \%$ of the patients in their VCD and control groups, respectively, had continuous telemetry monitoring for 4 days would have significantly reduced the AF detection rate, the primary end point of the study. Although statistically nonsignificant, the mixture of different myocardial preservation strategies used (crystalloid cardioplegia, blood cardioplegia, and off-pump) effectively reduced the advantage of the large number of patients in the study.

We conducted a study between January 2002 and April 2003 (Table 1) in which we compared the incidence of AF among 70 consecutive patients undergoing primary CABG with that among 70 consecutive patients who underwent VCD (with the same technique described by Melo and colleagues $^{1}$ ) in addition to primary CABG. All patients were operated by the same consultant surgeon with the same bypass method and myocardial preservation technique (antegrade-retrograde cold $\mathrm{St}$ Thomas' Hospital blood cardioplegia). All patients had continuous telemetry monitoring for 5 days after the operation. In con-

TABLE 1. Data and outcome after ventral cardiac denervation in patients undergoing CABG with or without VCD

\begin{tabular}{|c|c|c|c|}
\hline Preoperative variables & $\begin{array}{c}\text { VCD } \\
(n=70)\end{array}$ & $\begin{array}{l}\text { No VCD } \\
(n=70)\end{array}$ & $P$ value \\
\hline Age $(y$, mean $\pm S D)$ & $65 \pm 10$ & $65 \pm 9$ & .7 \\
\hline $\operatorname{Sex}(M / F)$ & $5: 1$ & $6: 1$ & .6 \\
\hline Disease severity (\%) & & & .8 \\
\hline Single vessel & $1 \%$ & $3 \%$ & \\
\hline Double vessel & $23 \%$ & $22 \%$ & \\
\hline Triple vessel & $76 \%$ & $75 \%$ & \\
\hline Left ventricular function (\%) & & & .5 \\
\hline$>50 \%$ & $76 \%$ & $80 \%$ & \\
\hline $50 \%-30 \%$ & $17 \%$ & $16 \%$ & \\
\hline$<30 \%$ & $7 \%$ & $4 \%$ & \\
\hline Myocardial infarction (\%) & & & .8 \\
\hline Never & $69 \%$ & $71 \%$ & \\
\hline$>30 \mathrm{~d}$ & $28 \%$ & $25 \%$ & \\
\hline $1-30 \mathrm{~d}$ & $3 \%$ & $4 \%$ & \\
\hline Diabetes & $16 \%$ & $13 \%$ & .6 \\
\hline Hypertension (\%) & $65 \%$ & $57 \%$ & .4 \\
\hline Chronic obstructive airway disease $(\%)$ & $10 \%$ & $11 \%$ & .8 \\
\hline Parsonnet score (mean \pm SD) & $7.1 \pm 5.5$ & $6.8 \pm 6.5$ & .9 \\
\hline EuroSCORE (mean $\pm \mathrm{SD}$ ) & $2.5 \pm 1.7$ & $2.3 \pm 1.7$ & .6 \\
\hline$\beta$-Blockers $(\%)$ & $69 \%$ & $72 \%$ & .4 \\
\hline Crossclamp time (min, mean $\pm S D)$ & $34.3 \pm 7.5$ & $33.4 \pm 7.5$ & 6 \\
\hline Bypass time (min, mean \pm SD) & $57 \pm 13.5$ & $54 \pm 12.2$ & .1 \\
\hline No. of grafts (mean \pm SD) & 2.8 & 2.9 & .9 \\
\hline Postoperative inotropes (\%) & $13 \%$ & $8 \%$ & .4 \\
\hline Reoperation (\%) & $1.4 \%$ & $1.4 \%$ & $>.999$ \\
\hline Total blood loss (mL, mean \pm SD) & $603 \pm 299$ & $648 \pm 412$ & .6 \\
\hline Length of stay $(d$, mean $\pm S D)$ & $7 \pm 0.8$ & $7.5 \pm 1.2$ & .8 \\
\hline$A F(\%)$ & $29 \%$ & $34 \%$ & .3 \\
\hline
\end{tabular}

